\title{
Sliding mode controller design for frequency regulation in an interconnected power system
}

\author{
Anand Kumar ${ }^{*}$, Md Nishat Anwar and Shekhar Kumar
}

\begin{abstract}
In this paper, a Sliding mode controller design method for frequency regulation in an interconnected power system is presented. A sliding surface having four parameters has been selected for the load frequency control (LFC) system model. In order to achieve an optimal result, the parameter of the controller is obtained by grey wolf optimization (GWO) and particle swarm optimization (PSO) techniques. The objective function for optimization has been considered as the integral of square of error of deviation in frequency and tie-line power exchange. The method has been validated through simulation of a single area as well as a multi-area power system. The performance of the Sliding mode controller has also been analyzed for parametric variation and random loading patterns. The performance of the proposed method is better than recently reported methods. The performance of the proposed Sliding mode controller via GWO has $88.91 \%$ improvement in peak value of frequency deviation over the method of Anwar and Pan in case study 1 and similar improvement has been observed over different case studies taken from the literature.
\end{abstract}

Keywords: Load frequency control, Sliding mode control (SMC), Grey wolf optimization, Particle swarm optimization, Multi-area power system

\section{Introduction}

In an interconnected power system, load frequency control (LFC) is necessary to keep the frequency of each area and the tie-line power exchange within the specified limit [1-3].

The main objective of LFC is to regulate the frequency and tie-line power flow within the control area. The main control challenges in LFC are system model parametric uncertainty, non-linearity present in a realistic power system, and load-disturbances [4-6].

Various control techniques have been used in LFC to address these control issues, like model predictive control (MPC) [7], internal model control (IMC) [8], twodegree of freedom IMC (2DoF-IMC) [9], H-infinity control [10, 11], SMC [12-15], active disturbance rejection

\footnotetext{
* Correspondence: anand.ee15@nitp.ac.in
Department of Electrical Engineering, National Institute of Technology Patna,

* Correspondence: anand.ee15@nitp.ac.in
Department of Electrical Engineering, National Institute of Technology Patna, Patna, Bihar, India
}

\section{Springer Open}

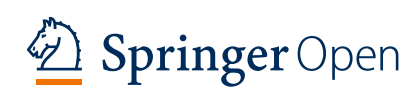

control (ADRC) $[16,17]$, the direct synthesis (DS) approach $[18,19]$ and artificial intelligence techniques [20] etc.

In recent times, the SMC design technique has gained more attention for being robust to modeling error, parametric variation, and external disturbance. These properties make SMC quite effective in many applications such as automotive systems [21], robotics [22], electric drives [23], wind-energy conversion systems [24, 25], process control [26, 27], unmanned aerial vehicles [28], etc. Recently the SMC technique has been used by many researchers to address the control issues of LFC [29-39].

Decentralized SMC has been designed for frequency control in a multi-area power system (MAPS), considering unmatched uncertainty, by Mi et al. [29]. Qian et al. [30] have improved control performance by using neural network-based integral SMC for the LFC of a non-linear power system. The method has been extended by Qian

(c) The Author(s). 2021 Open Access This article is licensed under a Creative Commons Attribution 4.0 International License, which permits use, sharing, adaptation, distribution and reproduction in any medium or format, as long as you give appropriate credit to the original author(s) and the source, provide a link to the Creative Commons licence, and indicate if changes were made. The images or other third party material in this article are included in the article's Creative Commons licence, unless indicated otherwise in a credit line to the material. If material is not included in the article's Creative Commons licence and your intended use is not permitted by statutory regulation or exceeds the permitted use, you will need to obtain permission directly from the copyright holder. To view a copy of this licence, visit http://creativecommons.org/licenses/by/4.0/. 
and Fan [31] for frequency control of a power system with renewable energy. A non-linear Sliding mode controller with matched and unmatched uncertainty has been proposed by Prasad et al. [32] for LFC of a threearea interconnected power system. Further, Prasad et al. [33] have extended their SMC design method to control the frequency of wind-integrated power systems.

A quasi decentralized SMC scheme has been proposed by $\mathrm{S}$. Yu et al. [34] for frequency regulation in a power system under load disturbance. Mu et al. [35] proposed an improved SMC based on adaptive dynamic programming for frequency stabilization in an LFC system with parametric uncertainties. A particle swarm optimization (PSO) technique is used to obtain an optimal value for the SMC controller. Sun et al. [36] proposed a robust $\mathrm{H}$ infinity SMC for frequency regulation in a MAPS with time delay. A new robust second-order SMC and extended disturbance observer has been proposed by Liao and $\mathrm{Xu}$ [37] for LFC in MAPS. This method first reduced the higher-order model to a lower-order model and then a new sliding surface is designed for SMC. Baghaee et al. [38] have designed a new decentralized SMC approach for frequency and voltage control in an islanded microgrid system. J. Guo [39] have used a fullorder SMC method to control the frequency of different area power systems. These reported schemes are generally based on a low-order model i.e. (first or secondorder) and for a higher-order system, the SMC controller may be designed by approximating the system to low-order one.

In this paper, a sliding mode controller is designed for a third-order system model. A sliding surface having four parameters is introduced and then the SMC control law is derived. This consists of two-parts: i.e., a continuous part $U_{C}(t)$ and a discontinuous part $U_{D}(t)$. The parameters of $U_{C}(t)$ and $U_{D}(t)$ have been obtained by optimizing the cost function as the integral of square error. To get the optimum value of the controller parameter, PSO and GWO optimization techniques have been used. The simulation results show that the proposed method outperforms recently reported methods.

The major contributions of the paper are as follows:

- A SMC controller has been designed for a thirdorder transfer function model and controller parameters have been obtained using PSO and GWO optimization techniques.

- The proposed SMC scheme has been used for load frequency control of single- area, two- area and four-area power systems.

- The proposed method is robust to parametric uncertainty and works satisfactorily under load disturbance and nonlinearity like GRC.
This paper is organized as follows: the LFC model for a single-area as well as a multi-area power system along with the proposed controller design method is given in Section 2. The simulation results are shown in Section 3 and the paper is concluded in Section 4.

\section{Sliding mode controller design}

The SMC technique is a special type of variable structure control that was initially presented by Utkin and Vadim [12]. The SMC is a robust control technique that can effectively compensate for plant model mismatch and load-disturbances. The desired behavior is represented through sliding surface $s(t)$ and the objective of the sliding mode controller is to drag the state of the system to the surface and keep it there.

The conventional unity negative feedback configuration consisting of plant and sliding mode controller is shown in Fig. 1. The symbols used in the block diagram have their usual meanings.

In this work, the sliding surface has been selected as an integro-differential equation given by

$$
s(t)=k_{1} \ddot{e}(t)+k_{2} \dot{e}(t)+k_{3} e(t)+k_{4} \int e(t) d t .
$$

Here, $e(t)$ is the tracking error, and $k_{1}, k_{2}, k_{3}$ and $k_{4}$ are the tuning parameters that are selected by the designer. The control objective in this case will be to ensure that $e(t)$ and its derivatives must be equal to zero at all times, once $s(t)$ is reached. So, to maintain $s(t)$ at a constant value, it is essential to make its derivative equal to zero which can be mathematically represented as

$$
\dot{s}(t)=0 .
$$

After selection of the sliding surface the control law $U(t)$ is developed by considering the condition in Eqs. (1) and (2), the SMC control law $U(t)$, consists of a continuous control part $U_{C}(t)$ and a discontinuous control part $U_{D}(t)$ as

$$
U(t)=U_{C}(t)+U_{D}(t) .
$$

The continuous component $U_{c}(t)$ is expressed as

$$
U_{C}(t)=f(x(t), r(t), e(t)) .
$$

where, $f(x(t), r(t), e(t))$ is the function of output, command signal and tracking error.

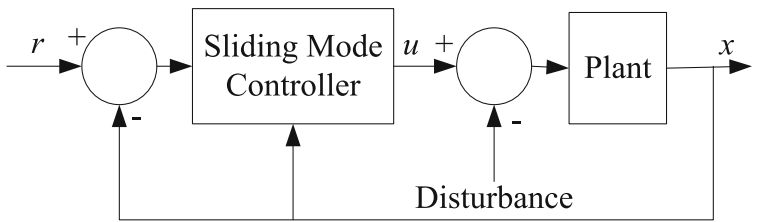

Fig. 1 Conventional feedback configuration of system model 
The discontinuous control law $U_{D}(t)$ includes a nonlinear element that denotes the switching element of the control law,

$$
U_{D}(t)=K_{D} \frac{s(t)}{|s(t)|+\delta}
$$

where $K_{D}$ and $\delta$ are the tuning parameters whose values are to be calculated.

The third-order transfer plant model has been considered as

$$
\frac{X(s)}{U_{c}(s)}=\frac{K}{\left(T_{1} s+1\right)\left(T_{2} s+1\right)\left(T_{3} s+1\right)} .
$$

Equation (6) can be written in differential equation form as

$$
\begin{aligned}
T_{1} T_{2} T_{3} \ddot{x}(t) & +\left(\left(T_{1}+T_{2}\right) T_{3}+T_{1} T_{2}\right) \ddot{x}(t) \\
& +\left(T_{1}+T_{2}+T_{3}\right) \dot{x}(t)+x(t)=K \quad \mathrm{U}_{\mathrm{c}}(\mathrm{t})
\end{aligned}
$$

Equation (2) can be simplified as

$$
\dot{s}(t)=k_{1} \ddot{e}(t)+k_{2} \ddot{e}(t)+k_{3} \dot{e}(t)+k_{4} e(t)=0
$$

The difference between the setpoint variable $r(t)$ and the controlled variable $x(t)$ is known as the tracking error $e(t)$; that is,

$$
e(t)=r(t)-x(t)
$$

Solving Eq. (7) for the third-order derivative of the controlled variable $\ddot{x}(t)$, in conjugation with Eq. (9) and replacing the expression into Eq. (8), the following equation is obtained:

$$
\begin{aligned}
& \dot{s}(t)=k_{1}\left[\begin{array}{l}
-\frac{K}{T_{1} T_{2} T_{3}} U_{c}(t)+\frac{\left(\left(T_{1}+T_{2}\right) T_{3}+T_{1} T_{2}\right)}{T_{1} T_{2} T_{3}} \ddot{x}(t) \\
+\frac{\left(T_{1}+T_{2}+T_{3}\right)}{T_{1} T_{2} T_{3}} \dot{x}(t)+\frac{x(t)}{T_{1} T_{2} T_{3}}
\end{array}\right] \\
&-k_{2} \ddot{x}(t)-k_{3} \dot{x}(t)-k_{4} x(t)=0
\end{aligned}
$$

The control law $U_{C}(t)$ can be derived as

$$
U_{C}(t)=\left[\begin{array}{l}
\ddot{x}(t)\left(\frac{\left(\left(T_{1}+T_{2}\right) T_{3}+T_{1} T_{2}\right)}{K}-\frac{k_{2}}{K k_{1}} T_{1} T_{2} T_{3}\right) \\
+\dot{x}(t)\left(\frac{T_{1}+T_{2}+T_{3}}{K}-\frac{k_{3}}{K k_{1}} T_{1} T_{2} T_{3}\right) \\
+x(t)\left(\frac{1}{K}-\frac{k_{4}}{K k_{1}} T_{1} T_{2} T_{3}\right)
\end{array}\right] .
$$

So, the resulting sliding mode controller is summarized as follows:

$$
U(t)=U_{C}(t)+K_{D} \frac{s(t)}{|s(t)|+\delta}
$$

where

$$
\begin{aligned}
s(t)= & \operatorname{sgn}(K) \\
& \times\left(k_{1} \ddot{e}(t)+k_{2} \dot{e}(t)+k_{3} e(t)+k_{4} \int_{0}^{t} e(t) d t\right)
\end{aligned}
$$

Here, $\operatorname{sgn}(K)$ is included in the system to guarantee the appropriate action of the control.

The tuning parameters $k_{1}, k_{2}, k_{3}, k_{4}, K_{D}$, and $\delta$ are obtained with the use of the metaheuristic optimization technique. Several researchers have used the metaheuristic optimization algorithm to determine the controller parameters in different control problems. The particle swarm optimization (PSO) technique is used by Mehta and Kaya [40] while the cuckoo search (CS) algorithm is adopted by Mehta and Rojas [41] to obtain the controller setting. The democratic joint operation algorithm [42], grouped grey wolf optimization [43], the dynamic leader-based collective intelligence algorithm [44] are some recently reported optimization techniques which have been successfully implemented in different control problems. Here, we have used PSO and GWO optimization techniques to obtain the controller parameters in Eq. (12).

The integral of square of the error signal (ISE) is taken as the objective function.

$$
I S E=\int(e(t))^{2} d t
$$

The proposed controller design method is implemented for the LFC problem. The plant model for the LFC consists of governor, turbine, generator, and load. The schematic diagram of a single area power system (SAPS) is shown in Fig. 2.

Along with the droop characteristics $R$, the system transfer function from $u$ to $\Delta f$ can be written as:

$$
\begin{aligned}
G(s) & =\frac{X}{U_{C}(s)}=\frac{G_{p} G_{t} G_{g}}{1+G_{p} G_{t} G_{g} / R} \\
& =\frac{k_{p}}{\left(\tau_{p} s+1\right)\left(\tau_{t} s+1\right)\left(\tau_{g} s+1\right)+k_{p} / R}
\end{aligned}
$$

The block diagram of a multi-area power system (MAPS) is shown in Fig. 3. The proposed controller design method can also be extended to MAPS where the goal of LFC is to regulate the frequency of each area and further to maintain the tie-line power flow exchange between the areas. With the variation of load in the power system the area frequency and tie-line power interchange vary. So, a combined parameter, area control error (ACE), is a linear combination of deviation in frequency response and tie-line power flow exchange, and is used in each LFC of MAPS.

The ACE is of the $i^{t h}$ control area is defined as 


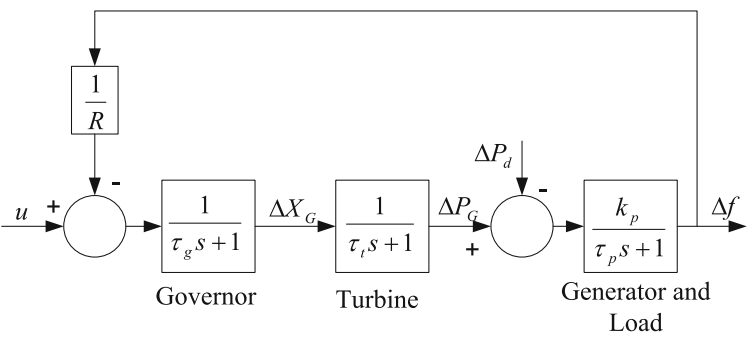

Fig. 2 Linearized model of single area power system

$$
A C E_{i}=\Delta P_{\text {tiei }}+\beta_{i} \Delta f_{i}
$$

where $\beta_{i}$ is the frequency bias coefficient.

For the system in Eq. (15) the continuous control law $U_{C}(t)$ can be obtained as

$$
\begin{gathered}
U_{C}(t)=\frac{1}{k_{p}}\left[\left(\tau_{g} \tau_{t}+\tau_{g} \tau_{p}+\tau_{p} \tau_{t}\right)-\frac{k_{2}}{k_{1}} \tau_{g} \tau_{t} \tau_{p}\right] \ddot{x}(t) \\
+\frac{1}{k_{p}}\left[\left(\tau_{g}+\tau_{t}+\tau_{p}\right)-\frac{k_{3}}{k_{1}} \tau_{g} \tau_{t} \tau_{p}\right] x(t) \\
+\left[\frac{k_{p}}{R}+1-\frac{k_{4}}{k_{1}} \tau_{g} \tau_{t} \tau_{p}\right] x(t)
\end{gathered}
$$

The resulting sliding mode controller can be written as:

$$
U(t)=U_{C}(t)+K_{D} \frac{s(t)}{|s(t)|+\delta}
$$

where,

$$
\begin{aligned}
s(t)= & -\operatorname{sgn}\left(k_{P}\right) \\
& \times\left(k_{1} \ddot{x}(t)+k_{2} \dot{x}(t)+k_{3} x(t)+k_{4} \int x(t) d t\right)
\end{aligned}
$$

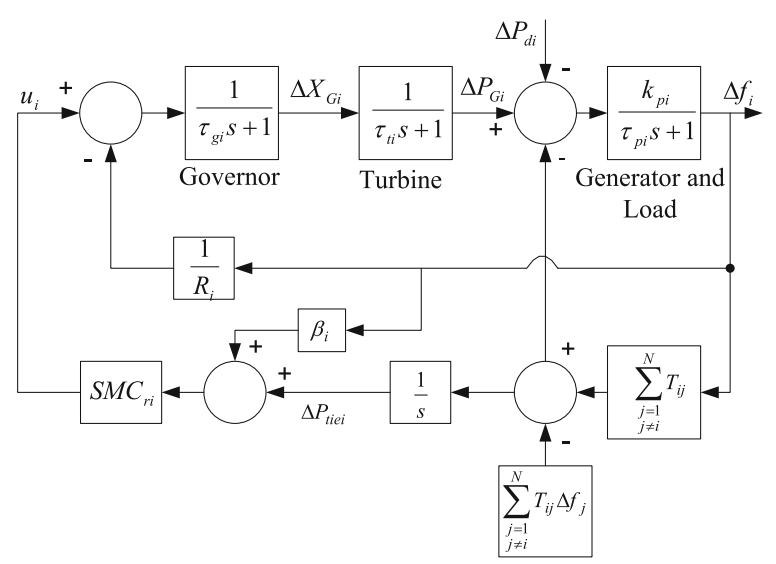

Fig. 3 Schematic diagram of control area $i$
To obtain the controller parameters $\left(k_{1}, k_{2}, k_{3}, k_{4}, K_{D}\right.$ and $\delta$ ) PSO and GWO techniques have been used. In the case of SAPS the ISE of the frequency deviation is taken as the objective function (Eq. 20) and in the case of MAPS, the ISE of the change in frequency in all the areas alongside the adjustment in tie-line power is taken as the objective function (Eq. 21).

$$
\begin{aligned}
& I S E=\int_{0}^{t_{\text {sim }}}(\Delta f)^{2} d t \\
& I S E=\int_{0}^{t_{\text {sim }}}\left(\Delta f_{1}^{2}+\Delta f_{2}^{2}+\ldots+\Delta f_{n}^{2}\right) d t \\
& +\int_{0}^{t_{\text {sim }}}\left(\Delta P_{\text {tie } 1}^{2}+\Delta P_{\text {tie } 2}^{2}+\ldots+\Delta P_{\text {tien }}^{2}\right) d t
\end{aligned}
$$

\section{Simulation results and discussion}

In this section, three SAPS, one two-area power system (TAPS), and one FAPS is considered for the simulation. The response obtained with the proposed method is compared with the recently reported methods in the literature. The performance has been evaluated in terms of peak value, settling time, percentage improvement in peak value, integral absolute error (IAE), integral of square error (ISE), integral time absolute error (ITAE) of the output response.

\subsection{Case study 1: single-area power system with non- reheated turbine (NRT)}

The parameters of the power system are taken from [18] as follows:

$$
k_{p}=120, \tau_{p}=20, \tau_{t}=0.3, \tau_{g}=0.08 \text { and } R=2.4
$$

The tuning parameters $k_{1}, k_{2}, k_{3}, k_{4}, K_{D}$, and $\delta$ of the proposed method as obtained from GWO are 0.01, $15.1687,110.8602,116.59,0.0064$, and 0.4270 respectively. The tuning parameters $k_{1}, k_{2}, k_{3}, k_{4}, K_{D}$, and $\delta$ of the proposed method as obtained from PSO are 0.8617, 33.5230, $245.306,680.97,3.4599$, and 0.4414 respectively.

To check the controller performance, a load disturbance $\Delta P_{d}=0.01$ p.u. is applied at $t=1 \mathrm{~s}$ in SAPS. The frequency response obtained with the proposed controller is shown in Fig. 4, and the comparison with Anwar and Pan [18] and Saxena and Hote [9] for case study 1 is reported in Table 1 . It is confirmed from figure and table that the proposed method has much improved performance over those two. The performance of the proposed SMC controller via GWO has $88.91 \%$ improvement in peak value of frequency deviation over the method of Anwar and Pan [18] in case study 1. 


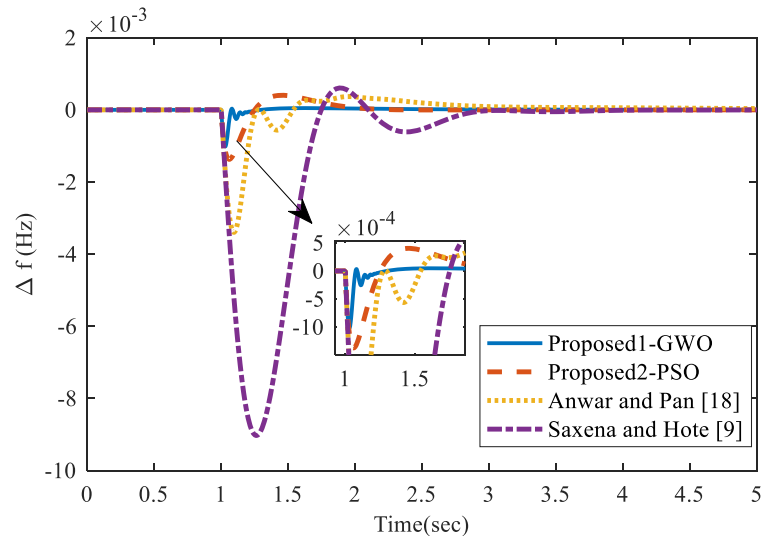

Fig. 4 Frequency regulation for case study 1

\subsection{Case study 2: single area power system with NRT}

The parameters of SAPS are taken from Anwar and Pan [18].

$$
k_{p}=1.25, \tau_{p}=12.5, \tau_{t}=0.5, \tau_{g}=0.2 \text { and } R=0.05
$$

The tuning parameters $k_{1}, k_{2}, k_{3}, k_{4}, K_{D}$, and $\delta$ of the proposed method as obtained from GWO are 0.0560, $1.9292,29.8476,84.8252,0.0157$, and 1.8729 respectively. The tuning parameters $k_{1}, k_{2}, k_{3}, k_{4}, K_{D}$, and $\delta$ of the proposed method as obtained from PSO are 0.01, 7.2728, 73.09, 242.13,0.4743, and 3.386 respectively.

A step load disturbance of magnitude $\Delta P_{d}=0.01$ p.u. is applied at $t=1 \mathrm{~s}$ in SAPS. The frequency response of the proposed method along with Padhan and Majhi [4] and Anwar and Pan [18] is shown in Fig. 5 and the performance analysis of the proposed method is reported in Table 2. Table 2 and Fig. 5 show that the proposed controller performs better in terms of peak value, settling time, ISE, IAE, and ITAE. The percentage improvement in the peak value of the proposed1-GWO method is 91.44\% than that of Padhan and Majhi [4].

Table 1 Comparison analysis for case study 1

\begin{tabular}{lllllll}
\hline Method & $\begin{array}{l}\text { Peak } \\
\text { Value } \\
\left(\times \mathbf{1 0}^{-3}\right)\end{array}$ & $\begin{array}{l}\text { Settling }) \\
\text { time } \\
\left(T_{s}\right) \text { sec. }\end{array}$ & & ISE & ITAE & $\begin{array}{l}\text { Percentage } \\
\text { Improvement } \\
\text { in peak value } \\
\text { w.r.t [18]. }\end{array}$ \\
\hline $\begin{array}{l}\text { Proposed1- } \\
\text { GWO }\end{array}$ & 1.0 & 1.12 & $1.72 \times$ & $1.3 \times$ & $5.6 \times$ & 88.91 \\
$\begin{array}{l}\text { Proposed2- } \\
\text { PSO }\end{array}$ & 1.37 & 1.75 & $3.53 \times$ & $1.87 \times$ & $5.1 \times$ & 84.80 \\
$\begin{array}{l}\text { Saxena and } \\
\text { Hote [9] }\end{array}$ & 3.39 & 2.5 & $1.4 \times$ & 0.001 & 0.002 & 58.40 \\
$\begin{array}{l}\text { Anwar and } \\
\text { Pan [18] }\end{array}$ & 9.02 & 2.73 & $2.6 \times$ & 0.004 & 0.006 & - \\
\hline
\end{tabular}

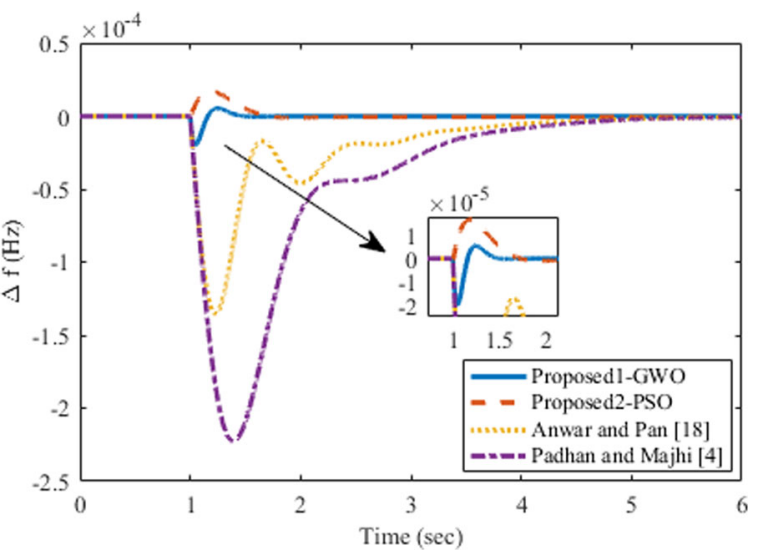

Fig. 5 Frequency regulation for case study 2

\subsection{Case study 3: single area power system with NRT} A SAPS with NRT is considered as having the following system parameters Anwar and Pan [18].

$$
k_{p}=1, \tau_{p}=10, \tau_{t}=7, \tau_{g}=0.2 \text { and } R=0.05
$$

The tuning parameters $k_{1}, k_{2}, k_{3}, k_{4}, K_{D}$, and $\delta$ of the proposed method as obtained from GWO are 1.50, $27.54,435.96,872.3759,1.02$, and 1.1962 respectively. The tuning parameters $k_{1}, k_{2}, k_{3}, k_{4}, K_{D}$, and $\delta$ of the proposed method as obtained from PSO are 1.195, $22.463,167.96,593.11,0.3808$, and 0.01 respectively.

To test the effectiveness of the proposed method, a unit step load $\Delta P_{d}=0.01$ p.u. is applied at $t=1 \mathrm{~s}$ in SAPS. The simulation response of the proposed method compared with that of Anwar and Pan [18] is shown in Fig. 6 and its detailed analysis is reported in Table 3.

From the above three case studies, it is seen clearly that the proposed method gave faster response with lower peak value. The performance of the proposed1GWO method is observed in terms of IAE, ISE, ITAE, and it is better than that of the proposed2-PSO, Anwar and Pan [18].

Table 2 Comparison analysis for case study 2

\begin{tabular}{lllllll}
\hline Method & $\begin{array}{l}\text { Peak Value } \\
\left(\times 10^{-4}\right)\end{array}$ & $\begin{array}{l}\text { Settling time } \\
\left(\mathrm{T}_{s}\right) \mathbf{s e c}\end{array}$ & ISE & $\begin{array}{l}\text { IAE } \\
\left(\times 10^{-4}\right)\end{array}$ & $\begin{array}{l}\text { ITAE } \\
\left(\times 10^{-4}\right)\end{array}$ & $\begin{array}{l}\text { Percentage } \\
\text { Improvement } \\
\text { in peak value } \\
\text { w.r.t [4] }\end{array}$ \\
\hline $\begin{array}{l}\text { Proposed1- } \\
\text { GWO }\end{array}$ & 0.19 & 1.4 & $\begin{array}{l}3.2 \times \\
10^{-11}\end{array}$ & 0.03 & 0.03 & 91.44 \\
$\begin{array}{l}\text { Proposed2- } \\
\text { PSO }\end{array}$ & 0.012 & 1.6 & $7.9 \times$ & 0.14 & 0.83 & 99.45 \\
& & & $10-$ & & & \\
$\begin{array}{l}\text { Anwar and } \\
\text { Pan [18] }\end{array}$ & 1.35 & 4.9 & $6.2 \times$ & 1.0 & 2.0 & 39.2 \\
$\begin{array}{l}\text { Padhan } \\
\text { and Majhi }\end{array}$ & 2.22 & 5.2 & $10^{-9}$ & & & \\
[4] & & $2.7 \times$ & 2.1 & 4.11 & - \\
\hline
\end{tabular}




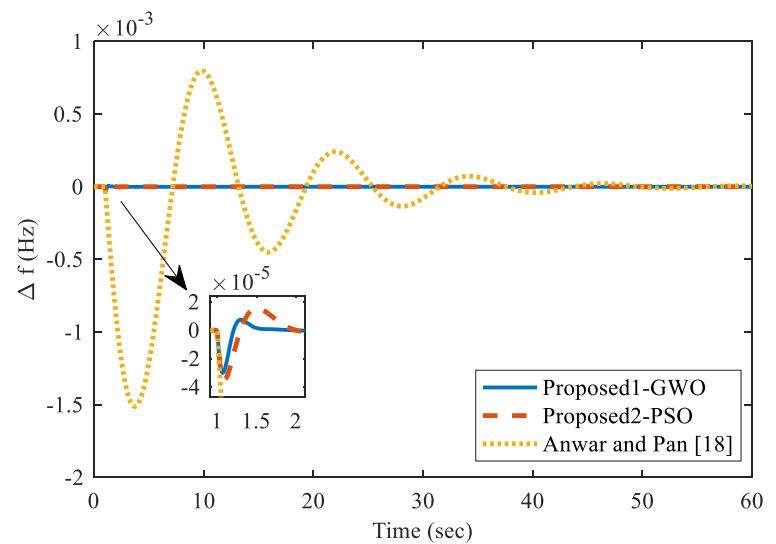

Fig. 6 Frequency regulation for case study 3

\subsection{Case study 4: single area power system with GRC}

As a non-linear component like GRC is added to a power system it will produce oscillation and sometimes it may become unstable. In the case study 4, Fig. 7 shows the GRC block is cascaded in a turbine transfer function model.

In case study 4, the effect of GRC is considered to exhibit the adequacy of the proposed method. The system parameters are the same as in case study 1 . In case study 4, the value of GRC is considered as 0.1 p.u. $/ \mathrm{min}=$ 0.0017 p.u./sec [18]. The controller parameters in this case study are the same as in case study 1 . The frequency deviation of the LFC system shows satisfactory performance in the presence of GRC, as shown in Fig. 8. The proposed method outperforms when considering the GRC effect.

3.5 Case study 5: two-area power system (TAPS) with NRT A TAPS is considered taking an identical system model for each area having the following system parameters $\mathrm{K}$. Lu et al. [6].

$$
\begin{aligned}
& k_{p 1}=k_{p 2}=120, \tau_{p 1}=\tau_{p 2}=20, \tau_{t 1}=\tau_{t 2}=0.3, \tau_{g 1}=\tau_{g 2}=0.08 \\
& R_{1}=R_{2}=2.4, \beta_{1}=\beta_{2}=0.425, T_{12}=T_{21}=0.545
\end{aligned}
$$

To illustrate the proposed method, five cases are taken from $\mathrm{K}$. Lu et al. [6]. Various cases are taken to analyze case study 5 , which is given in Table 4 . The block diagram of a two-area interconnected power system is

Table 3 Comparison analysis for case study 3

\begin{tabular}{lllllll}
\hline Method & $\begin{array}{l}\text { Peak Value } \\
\left(\times 10^{-4}\right)\end{array}$ & $\begin{array}{l}\text { Settling time } \\
\left(T_{s}\right) \mathbf{s e c}\end{array}$ & ISE & $\begin{array}{l}\text { IAE } \\
\left(\times 10^{-}\right. \\
4^{4}\end{array}$ & ITAE & $\begin{array}{l}\text { Percentage } \\
\text { Improvement in } \\
\text { peak value w.r.t } \\
{[18]}\end{array}$ \\
\hline $\begin{array}{l}\text { Proposed1- } \\
\text { GWO }\end{array}$ & 0.3 & 1.12 & $9.7 \times$ & 0.13 & $\begin{array}{l}8.6 \times \\
10^{-5}\end{array}$ & 98.0 \\
$\begin{array}{l}\text { Proposed2- } \\
\text { PSO }\end{array}$ & 0.35 & 1.20 & $2.3 \times$ & 0.01 & $9.72 \times$ & 97.66 \\
Anwar and & 15.0 & 42.5 & $90^{-10}$ & & $10^{-5}$ & \\
\begin{tabular}{l} 
Pan [18] \\
\hline
\end{tabular} & & $9.7 \times$ & 12.7 & 0.142 & - \\
\hline
\end{tabular}

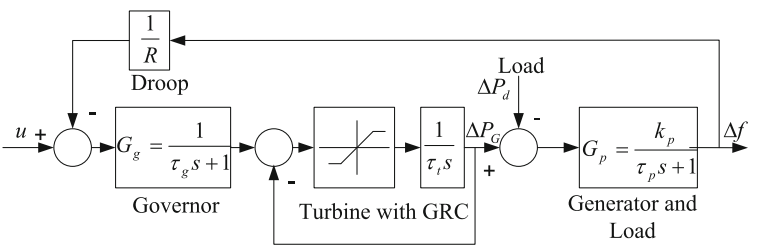

Fig. 7 Single-area power system with GRC block

shown in Fig. 9. The tuning parameters $k_{1}, k_{2}, k_{3}, k_{4}, K_{D}$, and $\delta$ of the proposed method as obtained from GWO are $0.3554,18.4423,156.7927,317.8682,0.8789$, and 3.3124 respectively. The tuning parameters $k_{1}, k_{2}, k_{3}, k_{4}$, $K_{D}$, and $\delta$ of the proposed method as obtained from PSO are 0.086, 9.797, 47.4837, 113.97, 2.2183, and 0.5419 respectively. The controller parameters for both areas are the same.

\subsection{Case 5a: 0.1 p.u. unit step load in area 1 and area 2 load $=0$}

In case $5 \mathrm{a}, 0.1$ p.u. unit step load in area 1 is taken at $\mathrm{t}=1 \mathrm{~s}$ to illustrate the performance of the proposed method through simulation results in TAPS.

The frequency deviation in area 1, area 2 and tie-line power flow between the two areas for case $5 \mathrm{a}$ is shown in Figs. 10, 11 and 12, respectively, and its response is compared with K. Lu et al. [6] and shows that the proposed1-GWO method gives the faster response and lower peak value for frequency regulation in TAPS.

\subsection{Case 5b: 0.1 p.u. unit step load in area 2 and area 1 load $=0$}

In case $5 \mathrm{~b}, 0.1$ p.u. the unit step load in area 2 is taken at $\mathrm{t}=1 \mathrm{~s}$ to illustrate the performance of the proposed method through simulation results in TAPS.

The frequency deviation in area 1, area 2 and tie-line power flow between the two areas for case $5 \mathrm{~b}$ is shown in Figs. 13, 14 and 15 respectively, and its response is

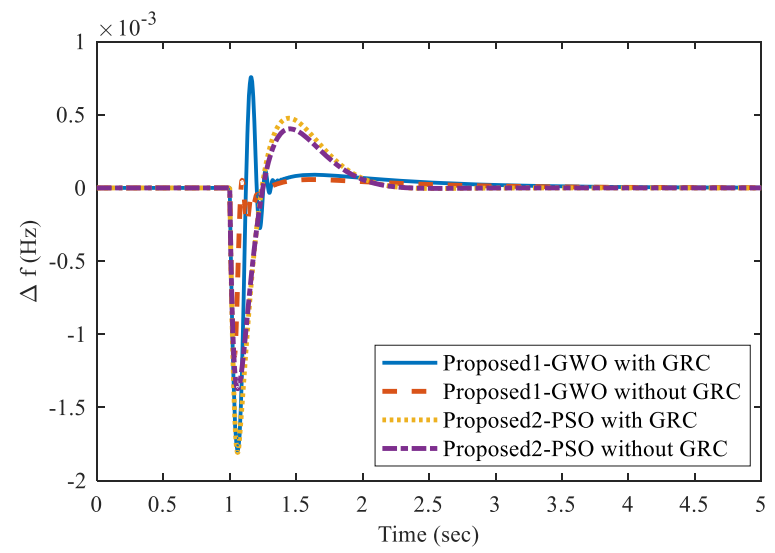

Fig. 8 Frequency regulation of SAPS with GRC 
Table 4 The conditions for test cases for case study 5

\begin{tabular}{ll}
\hline Case & Condition \\
\hline $\begin{array}{l}\text { Case } \\
5 a\end{array}$ & 0.1 p.u. step load in area 1. \\
Case & 0.1 p.u. step load in area 2. \\
$5 \mathrm{~b}$ & \\
Case & Area 1 and area 2 undergo 0.1 p.u. unit step load \\
$5 \mathrm{c}$ & simultaneously \\
Case & Perturbation in power system: $+50 \%$ perturbation in $T_{g \prime}+50 \%$ \\
$5 \mathrm{~d}$ & perturbation in $T_{12}+92 \%$ perturbation in $T_{12}$, with 0.1 p.u. step \\
& load in area 1. \\
Case & 0.1 p.u. step load in area 1 and random step load in area 2 \\
$5 \mathrm{e}$ & \\
\hline
\end{tabular}

compared with that of the proposed2-PSO, K. Lu et al. [6] and show that the proposed1-GWO method has the faster transient speed for frequency regulation in TAPS.

\subsection{Case 5c: 0.1 p.u. unit step load in area 1 and area 2} simultaneously

In case $5 \mathrm{c}$, area 1 and area 2 undergoing 0.1 p.u. unit step load simultaneously is taken to illustrate the performance of the proposed method through simulation results in TAPS.

Figure 16 shows the frequency regulation in area 1 and ACE in area 1 is shown in Fig. 17. Figures 16 and 17 show that the proposed1-GWO controller has muchimproved performance over that of the proposed2-PSO, K. Lu et al. [6].

3.9 Case $5 \mathrm{~d}:+50 \%$ perturbation in $T_{g},+50 \%$ perturbation in $T_{12},+92 \%$ perturbation in $T_{12}$ with 0.1 p.u. step load in area 1

In case $5 \mathrm{~d},+50 \%$ perturbation in $T_{g},+50 \%$ perturbation in $T_{12},+92 \%$ perturbation in $T_{12}$, with 0.1 p.u. step load in area 1 is taken to validate the performance of the proposed method through simulation results in TAPS.

Figure 18 shows the frequency regulation in area 1 with $+50 \%$ perturbation in $T_{g}$, Fig. 19 shows the frequency regulation in area 1 with $+50 \%$ perturbation in $T_{12}$ and Fig. 20 shows the frequency regulation in

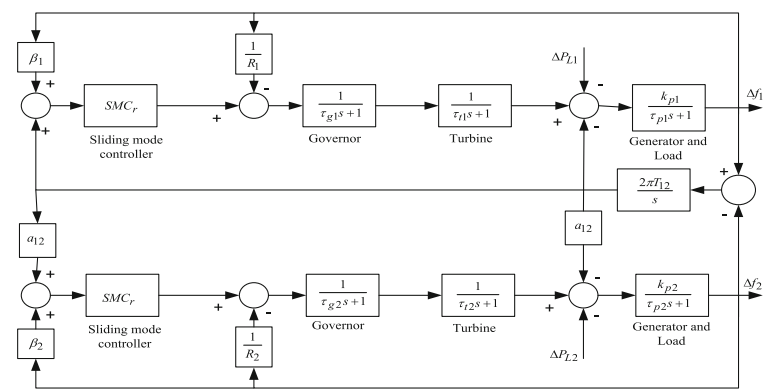

Fig. 9 Two-area interconnected power system

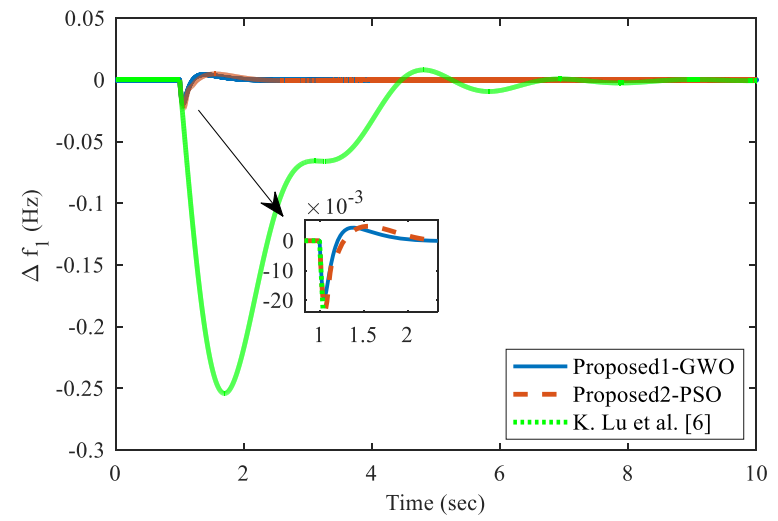

Fig. 10 Frequency regulation in area 1 for case 5a

area 1 with $+92 \%$ perturbation in $T_{12}$. From Figs. 18, 19 and 20 it can be seen that the proposed1-GWO method is more robust than the proposed2-PSO, K. $\mathrm{Lu}$ et al. [6]. It can be noted that there is not much effect on the response in the case of plant parameter variation and so we can confirm that the proposed scheme is more robust.

\subsection{Case 5e: 0.1 p.u. step load in area 1 and random step load in area 2}

In case 5 e, 0.1 p.u. step load in area 1 and random step load in area 2 is considered to validate the performance of the proposed method through simulation results in TAPS.

Random step load variation in area 2 is shown in Fig. 21. Frequency deviation in area-1, area 2 and tie-line power flow between the two areas for case $5 \mathrm{e}$ is shown in Figs. 22, 23 and 24 respectively, and its response is compared with that of the proposed2-PSO, K. Lu et al. [6] and confirm that the proposed1-GWO and the proposed2-PSO method is more robust for frequency regulation in TAPS.

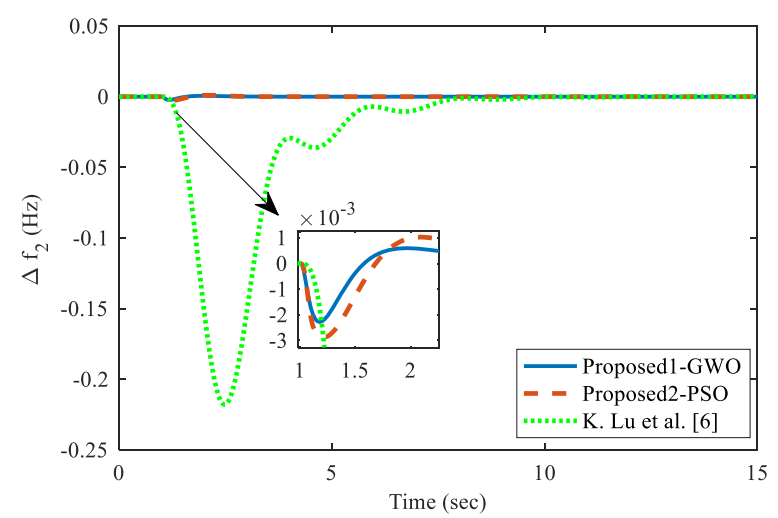

Fig. 11 Frequency regulation in area 2 for case $5 \mathrm{a}$ 


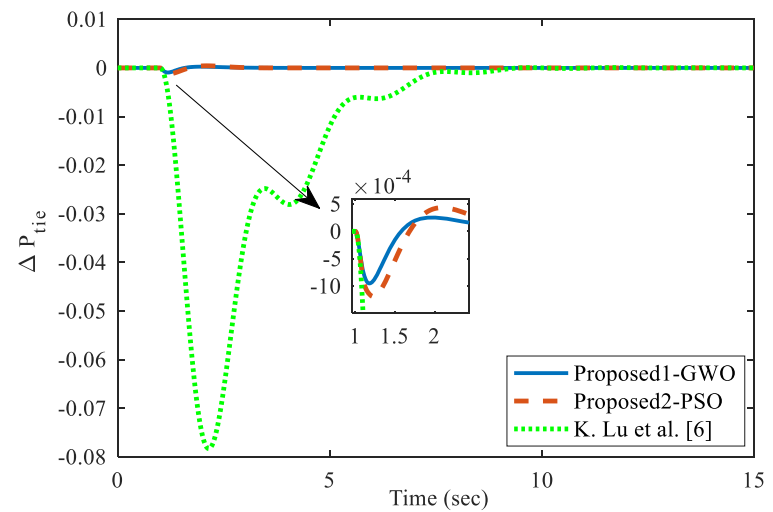

Fig. 12 Tie-line power flow for case $5 a$

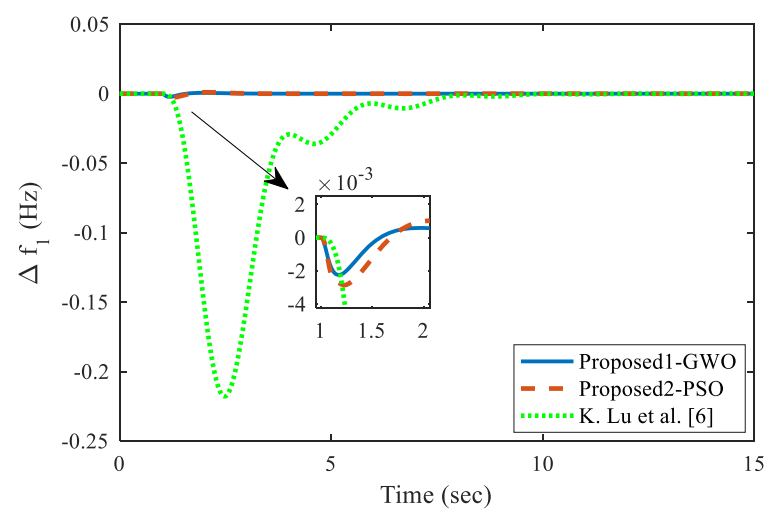

Fig. 13 Frequency regulation in area 1 for case 5b

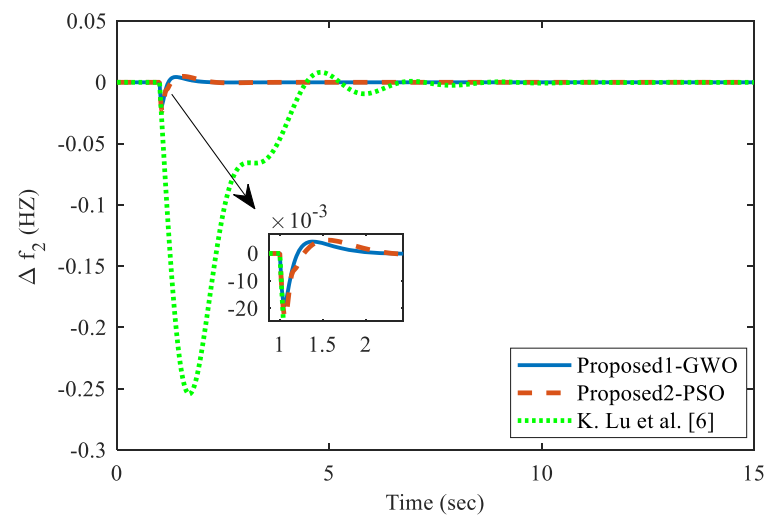

Fig. 14 Frequency regulation in area 2 for case 5b

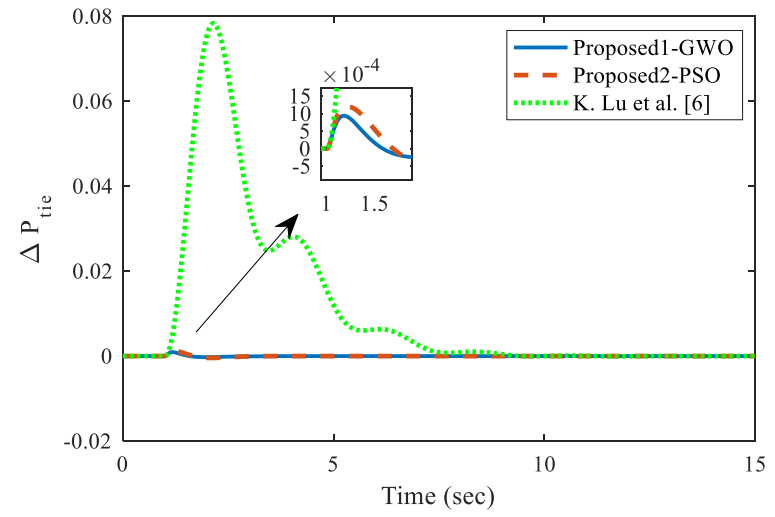

Fig. 15 Tie-line power flow for case 5b

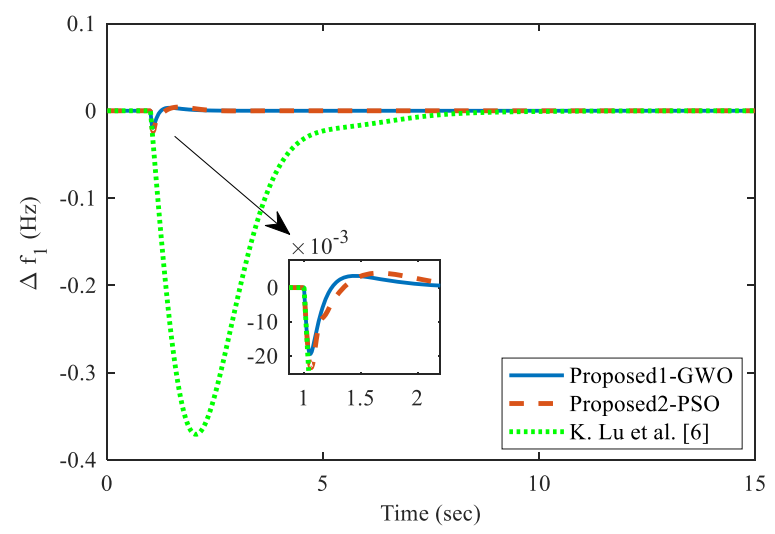

Fig. 16 Frequency regulation in area 1 for case $5 c$

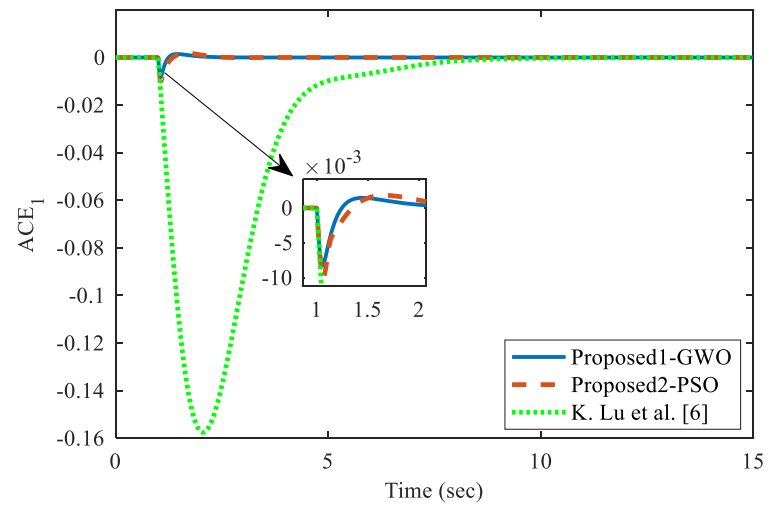

Fig. 17 Area control error in area 1 for case 5c 


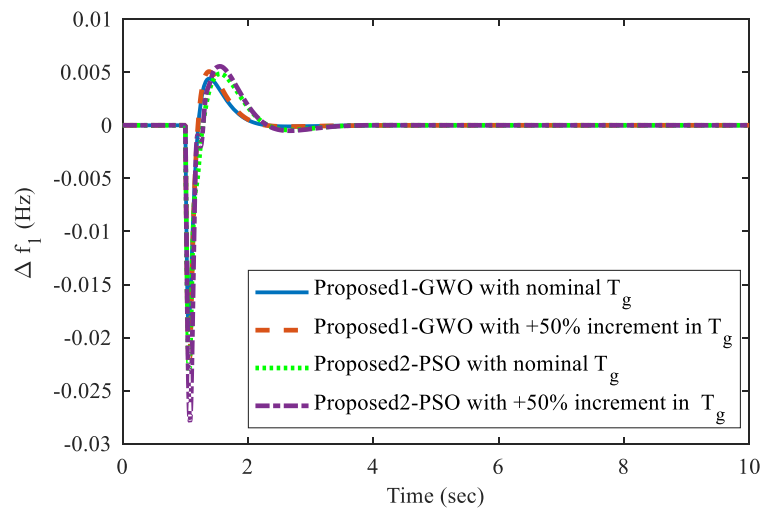

Fig. 18 Frequency regulation in area 1 with $+50 \%$ perturbation in $\mathrm{Tg}$ for case $5 \mathrm{~d}$

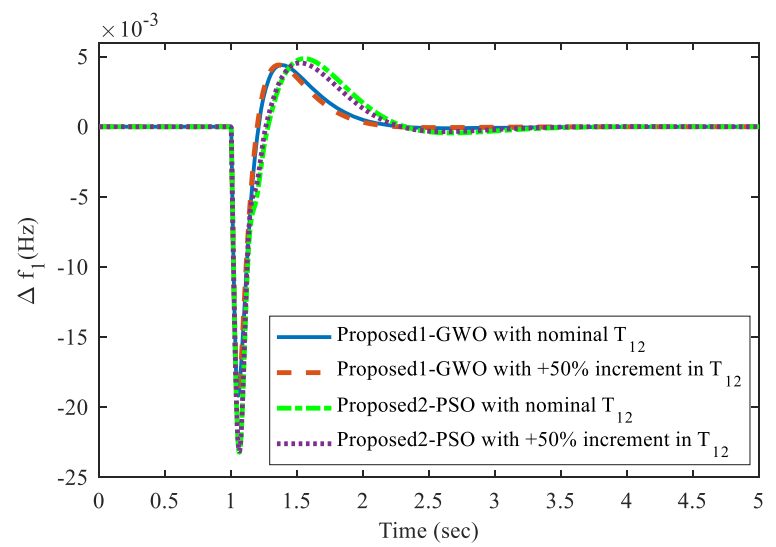

Fig. 19 Frequency regulation in area 1 with $+50 \%$ perturbation in $T_{12}$ for case $5 d$

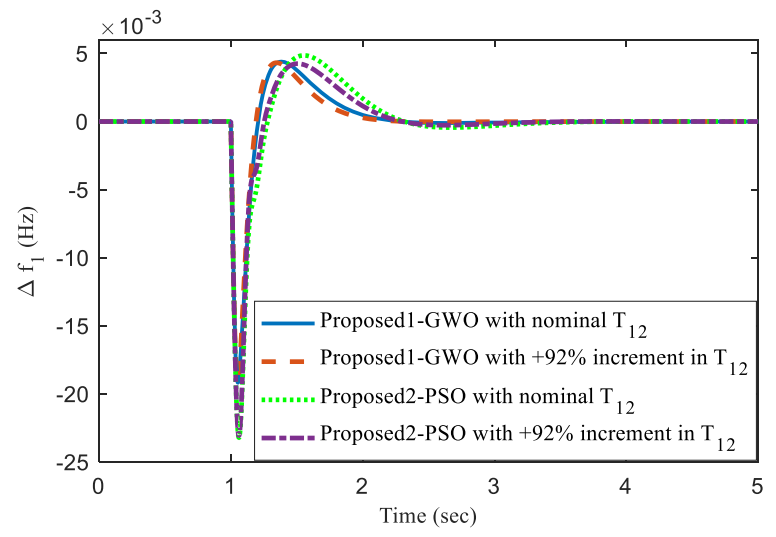

Fig. 20 Frequency regulation in area 1 with $+92 \%$ perturbation in $T_{12}$ for case $5 d$

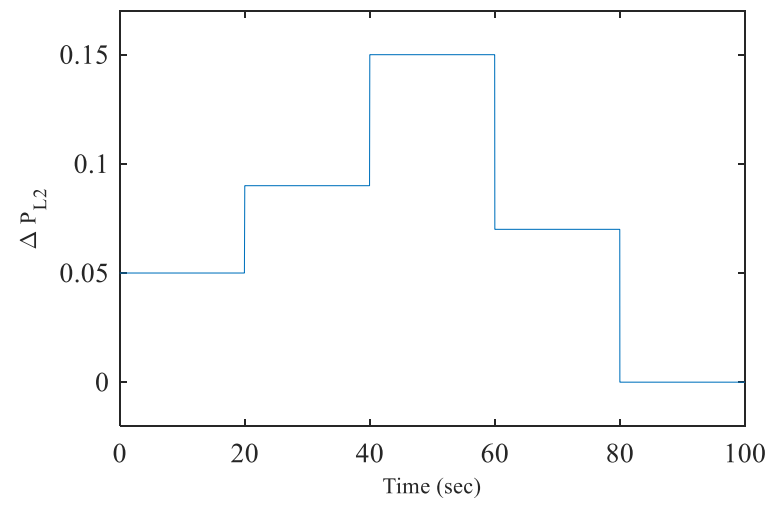

Fig. 21 Random step loading in area 2 for case 5 e under case study 5

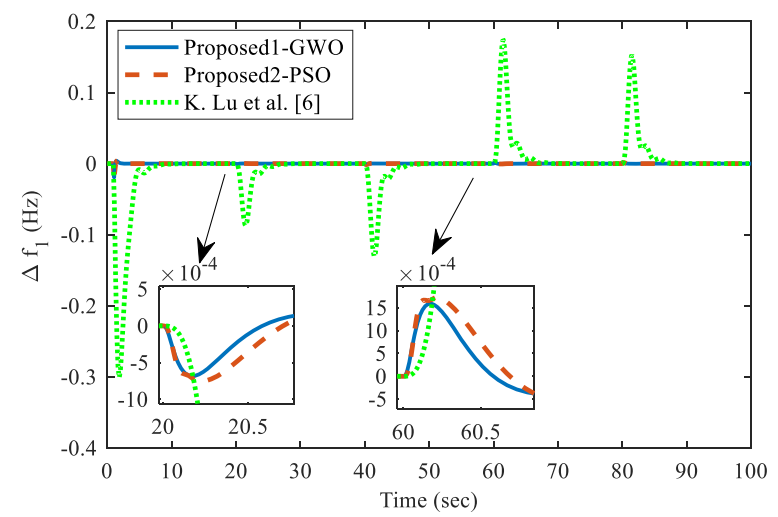

Fig. 22 Frequency deviation in area 1 for case 5 e under case study 5

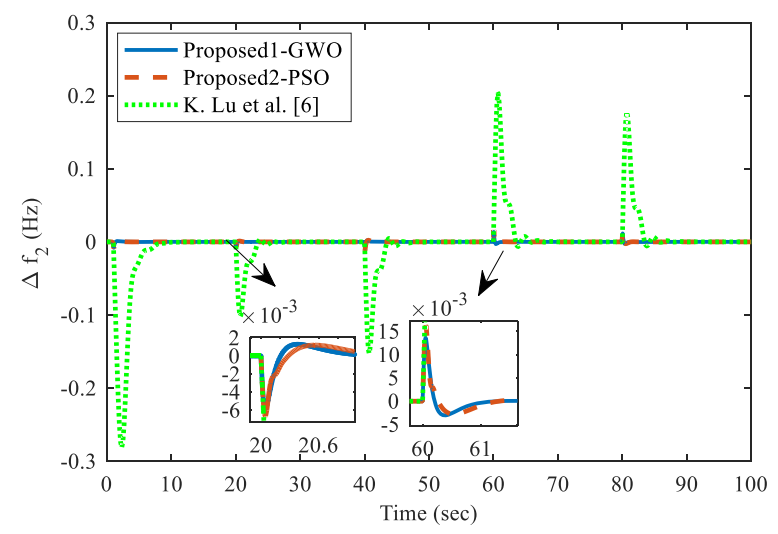

Fig. 23 Frequency deviation in area 2 for case 5 e under case study 5 


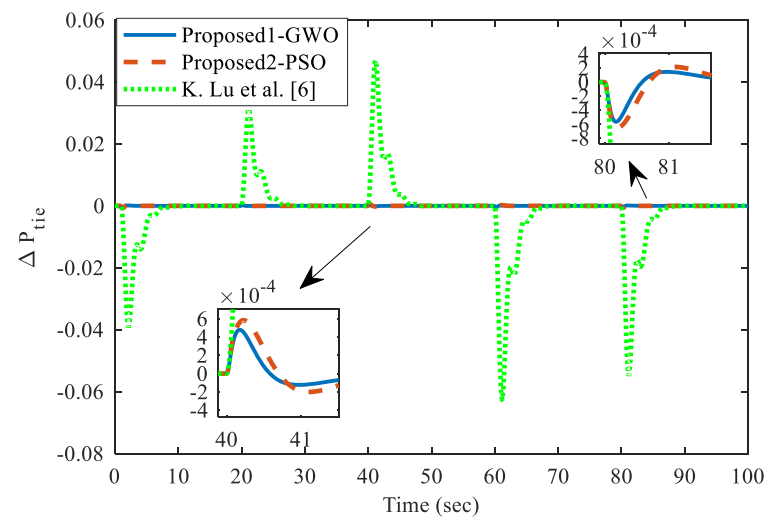

Fig. 24 Tie-line power flow between two areas for case $5 e$ under case study 5

Table 5 Parameters of four-area LFC system for case study 6

\begin{tabular}{llllll}
\hline Area & $\boldsymbol{R}(\mathrm{Hz} / \mathrm{pu} \mathrm{MW})$ & $\boldsymbol{\tau}_{\boldsymbol{g}}(\boldsymbol{s})$ & $\boldsymbol{\tau}_{\boldsymbol{t}}(\boldsymbol{s})$ & $\boldsymbol{\tau}_{\boldsymbol{p}}(\boldsymbol{s})$ & $\mathbf{k}_{\mathbf{p}}(\mathrm{Hz} / \mathbf{p u ~ M W})$ \\
\hline Area 1 & 2.4 & 0.08 & 0.3 & 20 & 120 \\
Area 2 & 2.7 & 0.072 & 0.33 & 25 & 112.5 \\
Area 3 & 2.5 & 0.07 & 0.35 & 20 & 125 \\
Area 4 & 2.0 & 0.085 & 0.375 & 15 & 115 \\
\hline
\end{tabular}

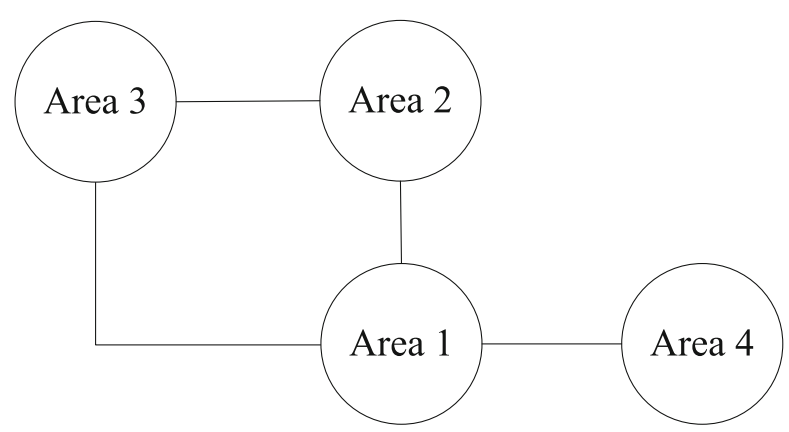

Fig. 25 Simplified diagram of a four-area power system

Table 6 Parameters of sliding mode controller based on GWO for FAPS

\begin{tabular}{lllllll}
\hline Area & $\boldsymbol{k}_{\boldsymbol{1}}$ & $\boldsymbol{K}_{\mathbf{2}}$ & $\boldsymbol{K}_{\mathbf{3}}$ & $\boldsymbol{K}_{\boldsymbol{4}}$ & $\boldsymbol{K}_{\boldsymbol{D}}$ & $\boldsymbol{\delta}$ \\
\hline Area 1 & 0.504 & 18.44 & 108.05 & 108.07 & 1.233 & 0.2903 \\
Area 2 & 0.180 & 12.75 & 110.4 & 79.24 & 0.835 & 0.451 \\
Area 3 & 0.252 & 4.697 & 26.89 & 64.40 & 0.239 & 0.454 \\
Area 4 & 0.811 & 14.04 & 178.3 & 577.6 & 0.398 & 0.318 \\
\hline
\end{tabular}

Table 7 Parameters of sliding mode controller based on PSO for FAPS

\begin{tabular}{lllllll}
\hline Area & $\boldsymbol{k}_{\mathbf{1}}$ & $\boldsymbol{K}_{\mathbf{2}}$ & $\boldsymbol{K}_{\mathbf{3}}$ & $\boldsymbol{K}_{\mathbf{4}}$ & $\boldsymbol{K}_{\boldsymbol{D}}$ & $\boldsymbol{\delta}$ \\
\hline Area 1 & 1.802 & 34.02 & 241.0 & 351.4 & 3.057 & 0.461 \\
Area 2 & 0.763 & 37.01 & 271.5 & 691.1 & 1.946 & 0.261 \\
Area 3 & 0.670 & 19.56 & 108.9 & 272.8 & 0.780 & 0.624 \\
Area 4 & 1.055 & 26.34 & 318.8 & 1047 & 0.670 & 0.847 \\
\hline
\end{tabular}
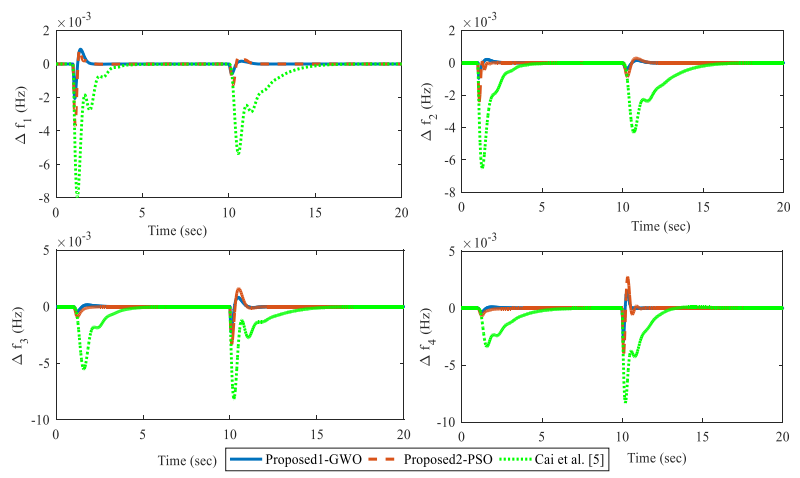

Fig. 26 Comparison of frequency deviation for FAPS in case study 6
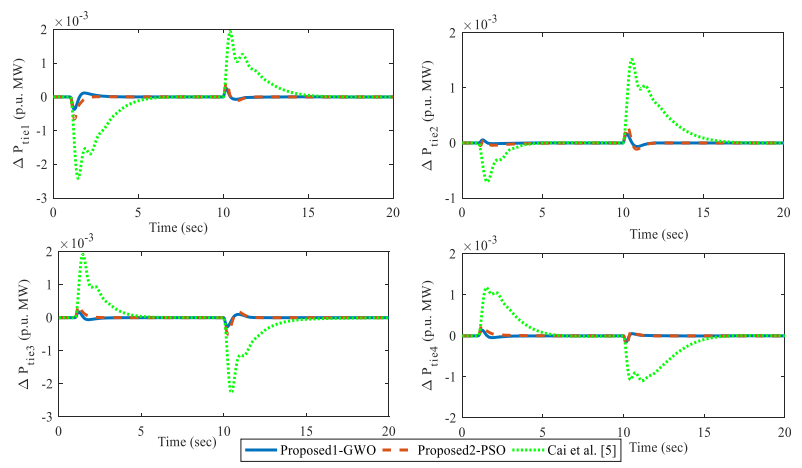

Fig. 27 Comparison of tie-line power flow for FAPS in case study 6 


\subsection{Case study 6: four-area power system (FAPS) with NRT}

A FAPS having the parameters as shown in Table 5 is taken from Cai et al. [5]. The block diagram interconnecting the four areas is shown in Fig. 25. The parameters of the sliding mode controllers obtained for the four areas from GWO and PSO are given in Tables 6 and 7. The simulation results of the proposed controller are observed by applying load demand $\Delta P_{L}=0.01$ p.u. $M W$ at $t=1 \mathrm{~s}$ in an areas no. 1,2 and load demand $\Delta P_{L}=0.01$ p.u.MW at $t=10 \mathrm{~s}$ in areas no. 3, 4 simultaneously. The comparison responses of proposed1-GWO with that of proposed2-PSO method and Cai et al. [5] for case study 6 is shown in Figs. 26 and 27. From these figures it can be seen that the proposed controller works very well in FAPS without any detoriation in system response.

\section{Conclusion}

In this paper, the sliding mode controller has been designed for a third-order system and implemented for frequency regulation in single-area, two-area, and four-area power systems. The optimal value of SMC controller parameters is obtained via the GWO and PSO optimization techniques. The efficacy of the proposed method has been analyzed with consideration of GRC, parametric uncertainty, and a random loading pattern. The proposed SMC controller via GWO performs better than the proposed SMC controller via PSO and other recently reported methods. From the simulation study, it is seen that the proposed method via GWO has $88.91 \%$ improvement in peak value of frequency deviation with that of Anwar and Pan while the proposed method via PSO has $84.80 \%$ improvement in case study 1 . Future work on the proposed method is to implement in LFC problem considering wind energy, hydro-energy, and photo-voltaic systems.

\section{Acknowledgements}

Not applicable.

\section{Authors' contributions}

All the authors have contributed in this manuscript. This manuscript is original research work. The author(s) read and approved the final manuscript.

Authors' information

Not applicable.

Funding

Not applicable.

\section{Availability of data and materials}

The datasets supporting the conclusions of this article are included within the article.

\section{Competing interests}

I declare that authors have no competing interests.
Received: 4 February 2020 Accepted: 18 January 2021

Published online: 26 February 2021

\section{References}

1. Kundur, P. (1994). Power system stability and control.

2. Kothari, D. P., \& Nagrath, I. J. (2009). Modern power system analysis. Tata McGraw-Hill Education Privated Limited, New Delhi.

3. Shankar, R., Pradhan, S. R., Chatterjee, K., \& Mandal, R. (2017). A comprehensive state of the art literature survey on LFC mechanism for power system. Renewable and Sustainable Energy Reviews, 76, 1185-1207. https://doi.org/10.1016/j.rser.2017.02.064.

4. Padhan, D. G., \& Majhi, S. (2013). A new control scheme for PID load frequency controller of single-area and multi-area power systems. ISA Transactions, 52, 242-251. https://doi.org/10.1016/j.isatra.2012.10.003.

5. Cai, L., He, Z., \& Hu, H. (2016). A new load frequency control method of multi-area power system via the viewpoints of port-Hamiltonian system and Cascade system. IEEE Transactions on Power Apparatus and Systems, 8950, 111. https://doi.org/10.1109/TPWRS.2016.2605007.

6. Lu, K., Zhou, W., Zeng, G., \& Zheng, Y. (2019). Constrained population extremal optimization-based robust load frequency control of multi-area interconnected power system. International Journal of Electrical Power \& Energy Systems, 105, 249-271. https://doi.org/10.1016/j.jiepes.2018.08.043.

7. Ma, M., Zhang, C., Liu, X., \& Chen, H. (2017). Distributed model predictive load frequency control of the multi-area power system after deregulation. IEEE Transactions on Industrial Electronics, 64, 5129-5139. https://doi.org/10. 1109/TIE.2016.2613923.

8. Saxena, S. (2019). Load frequency control strategy via fractional-order controller and reduced-order modeling. International Journal of Electrical Power \& Energy Systems, 104, 603-614. https://doi.org/10.1016/j.ijepes.2018. 07.005 .

9. Saxena, S., \& Hote, Y. V. (2017). Stabilization of perturbed system via IMC: An application to load frequency control. Control Engineering Practice, 64, 6173. https://doi.org/10.1016/j.conengprac.2017.04.002.

10. Peng, C., Li, J., \& Fei, M. (2017). Resilient event-triggering $\mathrm{H}_{\infty}$ load frequency control for multi-area power systems with energy-limited DoS attacks. IEEE Transactions on Power Apparatus and Systems, 32, 4110-4118. https://doi. org/10.1109/TPWRS.2016.2634122.

11. Ojaghi, P., \& Rahmani, M. (2017). LMI-based robust predictive load frequency control for power systems with communication delays. IEEE Transactions on Power Apparatus and Systems, 32, 4091-4100. https://doi.org/10.1109/TPWRS. 2017.2654453.

12. Utkin, V. I. (1977). Variable structure systems with sliding modes. IEEE Transactions on Automatic Control, 22, 212-222.

13. Mu, C., Tang, Y., He, H., \& Member, S. (2017). Improved sliding mode design for load frequency control of power system integrated an adaptive, (pp. 1-11). https://doi.org/10.1109/TIE.2017.2694396.

14. Rinaldi, G., Cucuzzella, M., \& Ferrara, A. (2017). Third order sliding mode observer-based approach for distributed optimal load frequency control, ( $\mathrm{p}$. 1456). https://doi.org/10.1109/LCSYS.2017.2712564.

15. Mi, Y., He, X., Hao, X., Li, Z., Fu, Y., Wang, C., \& Wang, J. (2019). Frequency control strategy of multi-area hybrid power system based on frequency division and sliding mode algorithm. IET Generation Transmission and Distribution, 13, 1145-1152. https://doi.org/10.1049/iet-gtd.2018.5145.

16. Liu, F., Li, Y., Cao, Y., She, J., \& Wu, M. (2016). A two-layer active disturbance rejection controller design for load frequency control of interconnected power system. IEEE Transactions on Power Apparatus and Systems, 31, 33203321. https://doi.org/10.1109/TPWRS.2015.2480005.

17. Benysek, G., Bojarski, J., Smolenski, R., Jarnut, M., \& Werminski, S. (2016). Application of stochastic decentralized active demand response (DADR) system for load frequency control. IEEE Transactions on Smart Grid, 3053, 11. https://doi.org/10.1109/TSG.2016.2574891.

18. Anwar, M. N., \& Pan, S. (2015). A new PID load frequency controller design method in frequency domain through direct synthesis approach. International Journal of Electrical Power \& Energy Systems, 67, 560-569. https://doi.org/10.1016/j.ijepes.2014.12.024.

19. Kumar, A., \& Anwar, M. N. (2019). Decentralized load-frequency controller design for a single as well as multi-area power system. Iranian Journal of Science and Technology, Transactions of Electrical Engineering. https://doi.org/ 10.1007/s40998-019-00246-y.

20. Sahoo, B. P., \& Panda, S. (2018). Improved grey wolf optimization technique for fuzzy aided PID controller design for power system frequency control. 
Sustainable Energy, Grids and Networks, 16, 278-299. https://doi.org/10.1016/ j.segan.2018.09.006.

21. Fu, L., State, T. O., \& Company, G. M. (2011). Automotive applications of sliding mode control, 1898-1903. https://doi.org/10.3182/20110828-6-IT1002.01276.

22. Taylor, P. (2007). Tracking control of non-linear systems using sliding surfaces, with application to robot manipulators, (pp. 37-41).

23. Utkin, V. I. (1993). Sliding mode control design principles and applications to electric drives. IEEE Transactions on Industrial Electronics, 40, 23-36.

24. Yang, B., Yu, T., Shu, H., Dong, J., \& Jiang, L. (2018). Robust sliding-mode control of wind energy conversion systems for optimal power extraction via nonlinear perturbation observers. Applied Energy, 210, 711-723. https://doi. org/10.1016/j.apenergy.2017.08.027.

25. Yang, B., Yu, T., Shu, H., Zhang, Y., Chen, J., Sang, Y., \& Jiang, L. (2018). Passivity-based sliding-mode control design for optimal power extraction of a PMSG based variable speed wind turbine. Renewable Energy, 119, 577-589. https://doi.org/10.1016/.j.renene.2017.12.047.

26. Camacho, O., \& Smith, C. A. (2000). Sliding mode control: An approach to regulate nonlinear chemical processes. ISA Transactions, 39, 205-218. https:// doi.org/10.1016/s0019-0578(99)00043-9.

27. Kaya, I. (2007). Sliding-mode control of stable processes. Industrial and Engineering Chemistry Research, 46, 571-578. https://doi.org/10.1021/ ie0607806.

28. Geng, J., Sheng, Y., \& Liu, X. (2014). Finite-time sliding mode attitude control for a reentry vehicle with blended aerodynamic surfaces and a reaction control system. Chinese Journal of Aeronautics, 27, 964-976. https://doi.org/ 10.1016/j.cja.2014.03.013.

29. Mi, Y., Fu, Y., Wang, C., \& Wang, P. (2013). Decentralized sliding mode load frequency control for multi-area power systems. IEEE Transactions on Power Apparatus and Systems, 28, 4301-4309. https://doi.org/10.1109/TPWRS.2013. 2277131.

30. Qian, D., Tong, S., Liu, H., \& Liu, X. (2016). Load frequency control by neuralnetwork-based integral sliding mode for nonlinear power systems with wind turbines. Neurocomputing, 173, 875-885. https://doi.org/10.1016/j. neucom.2015.08.043.

31. Qian, D., \& Fan, G. (2018). Neural-network-based terminal sliding mode control for frequency stabilization of renewable power systems. IEEE/CAA Journal of Automatica Sinica, 5, 706-717. https://doi.org/10.1109/JAS.2018. 7511078.

32. Prasad, S., Purwar, S., \& Kishor, N. (2017). Non-linear sliding mode load frequency control in multi-area power system. Control Engineering Practice, 61, 81-92. https://doi.org/10.1016/j.conengprac.2017.02.001.

33. Prasad, S., Purwar, S., \& Kishor, N. (2019). Non-linear sliding mode control for frequency regulation with variable- speed wind turbine systems. Electrical Power and Energy Systems, 107, 19-33. https://doi.org/10.1016/j.jijepes.2018. 11.005 .

34. Yu, S., Chau, T. K., Fernando, T., Savkin, A. V., \& Iu, H. H. C. (2017) Novel quasi-decentralized SMC-based frequency and voltage stability enhancement strategies using valve position control and FACTS device. IEEE Access, 5, 946-955. https://doi.org/10.1109/ACCESS.2016. 2622709.

35. Mu, C., Tang, Y., \& He, H. (2017). Improved sliding mode design for load frequency control of power system integrated an adaptive learning strategy. IEEE Transactions on Industrial Electronics, 64, 6742-6751. https://doi.org/10. 1109/TIE.2017.2694396.

36. Sun, Y., Wang, Y., Wei, Z., Sun, G., \& Wu, X. (2018). Robust H -infinity load frequency control of multi-area power system with time delay: A sliding mode control approach. IEEE/CAA Journal of Automatica Sinica, 5, 610-617. https://doi.org/10.1109/JAS.2017.7510649.

37. Liao, K., \& Xu, Y. (2018). A robust load frequency control scheme for power systems based on second-order sliding mode and extended disturbance observer. IEEE Transactions on Industrial Informatics, 14, 3076-3086. https:// doi.org/10.1109/TII.2017.2771487.

38. Baghaee, H. R., Mirsalim, M., Gharehpetian, G. B., \& Talebi, H. A. (2018). Decentralized sliding mode control of WG/PV/FC microgrids under unbalanced and nonlinear load conditions for on- and off-grid modes. IEEE Systems Journal, 12, 3108-3119. https://doi.org/10.1109/JSYST.2017. 2761792.

39. Guo, J. (2019). Application of full order sliding mode control based on different areas power system with load frequency control. ISA Transactions, 92, 23-34. https://doi.org/10.1016/j.isatra.2019.01.036.
40. Mehta, U. (2017). Smith predictor with sliding mode control for processes with large dead times. Journal of Electrical Engineering, 68, 463-469. https:// doi.org/10.1515/jee-2017.

41. Mehta, U., \& Rojas, R. (2017). Smith predictor based sliding mode control for a class of unstable processes. Transactions of the Institute of Measurement and Control, 39, 706-714. https://doi.org/10.1177/ 0142331215619973

42. Yang, B., Yu, T., Shu, H., Zhang, X., Qu, K., \& Jiang, L. (2018). Democratic joint operations algorithm for optimal power extraction of PMSG based wind energy conversion system. Energy Conversion and Management, 159, 312326. https://doi.org/10.1016/..enconman.2017.12.090.

43. Yang, B., Zhang, X., Yu, T., Shu, H., \& Fang, Z. (2017). Grouped grey wolf optimizer for maximum power point tracking of doubly-fed induction generator based wind turbine. Energy Conversion and Management, 133, 427-443. https://doi.org/10.1016/j.enconman.2016. 10.062

44. Yang, B., Yu, T., Zhang, X., Li, H., Shu, H., Sang, Y., \& Jiang, L. (2019). Dynamic leader based collective intelligence for maximum power point tracking of PV systems affected by partial shading condition. Energy Conversion and Management, 179, 286-303. https://doi.org/10.1016/j. enconman.2018.10.074.

\section{Submit your manuscript to a SpringerOpen ${ }^{\circ}$ journal and benefit from:}

- Convenient online submission

- Rigorous peer review

- Open access: articles freely available online

- High visibility within the field

- Retaining the copyright to your article

Submit your next manuscript at $\boldsymbol{\nabla}$ springeropen.com 